Voix et Images

voixetimages

\title{
Le Vieux Chagrin de Jacques Poulin
}

\section{Anne Marie Miraglia}

Volume 16, numéro 1 (46), automne 1990

Les correspondants littéraires d'Alfred DesRochers

URI : https://id.erudit.org/iderudit/200887ar

DOI : https://doi.org/10.7202/200887ar

Aller au sommaire du numéro

Éditeur(s)

Université du Québec à Montréal

ISSN

0318-9201 (imprimé)

1705-933X (numérique)

Découvrir la revue

Citer cet article

Miraglia, A. M. (1990). Le Vieux Chagrin de Jacques Poulin. Voix et Images, 16(1),

170-172. https://doi.org/10.7202/200887ar d'utilisation que vous pouvez consulter en ligne.

https://apropos.erudit.org/fr/usagers/politique-dutilisation/ 


\section{Le Vieux Chagrin de Jacques Poulin}

\section{par Anne Marie Miraglia, université Queen's}

C'est enveloppé dans une couverture étroite, sombre et vieillotte, que le Vieux Chagrin ${ }^{1}$ de Jacques Poulin parut enfin. Le roman raconte l'histoire d'un homme partagé, déchiré entre des désirs contradictoires (p. 30). C'est aussi l'histoire d'un écrivain, d'un maniaque des mots (p. 28) en proie aux affres de la création. Ainsi, comme les romans pouliniens antérieurs, le Vieux Chagrin porte effectivement sur la problématique de l'écriture. Son romancier fictif ressemble en cela aux autres scripteurs pouliniens - Amadou, Teddy, Jack Waterman - et en particulier à Noël du Cœur de la baleine bleue et à Jimmy du roman du même nom. Écrire, traduire et raconter une histoire posent nécessairement le même problème, celui de la maîtrise du matériau linguistique: les mots, dit Jim, sont indépendants comme les chats [...] vous avez beau les aimer, les flatter, leur parler doucement, ils s'échappent et partent à l'aventure (p. 29). Aussi Jim, dont le but est d'écrire une histoire d'amour, perdil souvent son ascendant sur le récit. Les rapports de ses personnages se transforment, malgré lui, en amitié et en tendresse. Et Jim a la vague impression qu'un autre écrit à sa place.

Le Vieux Chagrin revient donc forcément sur la question de la solitude et d'une certaine immobilité propices au travail de l'écrivain. Il se détourne apparemment de Volkswagen Blues où le grand voyage à travers l'Amérique vise autant un nouveau sujet de roman que la quête du frère et d'une nouvelle identité. Les deux textes partagent toutefois une certaine affinité fondée moins sur les 
allusions, dans le Vieux Chagrin, à l'aventure américaine que sur la récurrence de thèmes et de personnages typiquement pouliniens. Il s'agit, en particulier, des thèmes de la tendresse, des rapports humains, de l'enfance et du bonheur, de la représentation d'un scripteur doux mais aliéné vis-à-vis d'autrui, d'une jeune femme avide de lectures, d'une mère-poule androgyne et d'un frère plutôt chimérique.

Dans le Vieux Chagrin, Jacques Poulin redécouvre le «je», le procédé narratif de ses trois premiers romans. Il en résulte que l'usage de cette voix narrative nous rapproche davantage de l'auteur. Or, dans le Vieux Chagrin, comme dans Volkswagen Blues, l'on retrouve l'expression du vieillissement, de l'incommunicabilité des êtres et d'une insatisfaction vis-à-vis de soi-même (p. 20) sur le plan intime et professionnel débouchant sur la représentation d'un chagrin amoureux qui, quoique brièvement évoqué dans Volkswagen Blues, ne hante pas moins, sous une forme ou une autre, tous les romans de Jacques Poulin depuis Mon cheval pour un royaume.

L'échec de l'amour, le délaissement de l'écrivain semblent être, dans le Vieux Chagrin, au centre même du problème de la création littéraire. Et cela non seulement parce que la rupture du couple s'annonce pour la première fois dans le cadre de la thématique de la production romanesque, mais aussi parce qu'il est impossible pour Jim d'écrire une histoire d'amour sans être amoureux lui-même. Les intertextes de Colette (Chéri) et d'Ernest Hemingway (le Vieil Homme et la mer, la Grande Rivière au cœur double) sont évoqués en rapport avec le départ de la femme de Jim. Chéri, par exemple, fait surgir chez Jim une image douloureuse qui revient comme un leitmotiv: une femme encore jeune, qui allait partir avec un autre, enlevait ses livres d'une bibliothèque, laissant partout sur les rayons des vides qui ressemblaient à des brèches dans un mur de brique (p. 33; voir aussi p. 49 et p. 92). D'autre part, l'ancien spécialiste d'Ernest Hemingway admet que l'écrivain doit s'en tenir aux sujets qu'il connaît lui-même et que pour mieux maîtriser son récit, il lui faut devenir amoureux.

L'occasion se présente lorsqu'un jour Jim suit des traces de pas menant à la caverne de son enfance (la caverne d'Ali Baba) où des allumettes, une bougie et les contes des Mille et Une Nuits (déjà évoqués dans Faites de beaux rêves) annoncent l'âme de quelqu'un. Jim tombe bientôt amoureux de Marika dont l'existence fragile ne tient qu'à des empreintes sur le sable et à un voilier baptisé Dinarzade (le nom de la sœur de Schéhérazade). Marika partage la vie de Jim seulement le temps d'un été, le temps que durent sa lecture des Mille et Une Nuits (p. 123, p. 150) et ses réparations au voilier. En dépit de plusieurs tentatives de communication, Jim ne verra Marika qu'en rêve et l'on est porté à croire que cette femme 
mystérieuse n'est que la création d'un pauvre solitaire, inquiet de ce que la vie ne lui donnera plus jamais l'occasion d'aimer (p. 24).

En fait, Jim en vient à douter de l'existence de Marika et à voir en elle la projection d'un désir, une partie de [lui]-même, [s]a moitié féminine, [sa] douce moitié (p. 153), son âme sœur. Le Vieux Chagrin prend ainsi la forme d'une quête de soi, d'une quête proprement spirituelle. Aimer Marika c'est s'aimer soi-même, se valoriser: c'est retrouver l'envie de vivre (p. 134), retrouver le bonheur en soi-même (p. 133). Aimer Marika c'est, en somme, neutraliser les ravages du dépit amoureux (p. 95, 97) et essayer, pour la troisième fois, d'écrire la plus belle histoire d'amour qui ait jamais été écrite (p. 154). Ce nouvel effort s'appuie, cependant, sur le matériau des tentatives précédentes (p. 145) et sur les débris de sa propre vie (p. 113), car l'écrivain construit son œuvre à partir de tous les éléments qui lui tombent sous la main (p. 43). Il semble que cet ultime effort aboutisse à l'écriture du Vieux Chagrin, que le texte s'autoréfère, qu'il expose et commente sa propre production, laquelle amalgame au moins trois récits à la fois distincts et entremêlés: d'abord celui qui prend pour objet les problèmes de la création littéraire, un second portant sur Marika, et un troisième que j’ai passé sous silence jusqu'à présent, celui de l'adoption par Jim de la Petite.

C'est en effet la Petite et non pas Marika qui fait redémarrer l'histoire qu'écrit Jim (p. 43). Enfant abandonnée, traumatisée, en quête d'affection et, aussi, d'une famille, la Petite assaille Jim de questions, le contraint à revenir sur son passé, sur son enfance (p. 89) ainsi que sur le déchirement de l'échec conjugal: Quand ma femme est partie avec Superman [...] c'était comme si tout le monde m'avait abandonné et comme si je n'avais plus aucune valeur (p. 97). Ensemble, Jim et la Petite arrivent à satisfaire leur besoin de tendresse, de chaleur humaine et cela grâce à Bungalow, femme forte et douce, qui leur apprend à mieux s'aimer.

Il en résulte que l'histoire d'amour qu'écrit Jim reprend son élan. Mais elle ne porte pas sur l'amour en tant que passion mais l'amour en tant que tendresse (p. 98) et dont l'écriture contribue, tel que le veut Jim, à l'avènement d'un monde nouveau [...], un monde où l'agressivité, entendue non pas comme l'expression d'une hostilité à l'égard d'autrui, mais plutôt comme un goût de vivre, allait être au service de l'amour (p. 139). Jamais ne s'est exprimée aussi clairement la raison d'être de l'écriture poulinienne. 